\title{
El security interest como forma de acceso al crédito: ¿por qué no regularlo detalladamente en el derecho uruguayo?
}

The Security Interest as another way to access credit: should we regulate it in Uruguay?

Inés Payssé Terra

Universidad Católica del Uruguay

ORCID: 0000-0002-1153-5292

Correo: ines.paysse@ucu.edu.uy

Recibido: $17 / 08 / 2021$

Aceptado: 12/10/2021

Resumen: El security interest es una herramienta para facilitar el crédito, que permite contar con una garantía real sobre un amplio rango de bienes muebles. En este artículo se aborda la detallada regulación y la facilidad y practicidad con la cual se constituye un security interest y luego se ejecuta el security interest en caso de incumplimiento, según lo dispuesto en el capítulo 9 del Código de Comercio Uniforme de Estados Unidos. Este análisis resalta cómo en Uruguay la Ley de Prenda sin Desplazamiento (n. ${ }^{\circ} 17.228$ ) del año 2000 ha importado este concepto anglosajón parcialmente, siendo necesarios determinados cambios para su cabal aplicación.

Palabras clave: crédito; garantías mobiliarias; prenda sin desplazamiento; operación garantizada; derecho anglosajón.

\begin{abstract}
The Security Interest, thoroughly regulated under article 9 of the Uniform Commercial Code of the USA, allows debtors and creditors to engage in secured transactions, where a wide range of assets may serve as collateral, avoiding the risk of a debtor's default, thus enhancing the provision of credit. This article analyses article 9 and highlights the simplicity of this institute, stressing the difficulties and required amendments that should be made to the Uruguayan Pledges Without Transfer of Possession Act (n. ${ }^{\circ}$ 17228) of the year 2000, which only partially imported the security interest model.
\end{abstract}

Keywords: credit; security interest; pledge without transfer of possession; secured transactions; Anglo-Saxon Law. 


\section{¿Por qué estudiar el security interest? ${ }^{1}$}

El security interest inicia la llamada "tercera generación de garantías reales mobiliarias" (De Cores, 2008, p. 96), siendo la primera generación la prenda posesoria en la cual es necesaria la transferencia de la posesión a los efectos de la publicidad de la prenda ${ }^{2}$ la segunda generación, la prenda sin desplazamiento aplicada solo a algunos bienes como excepción; ${ }^{3}$ y la tercera generación, la actual, que implica la aplicación de la prenda sin desplazamiento en forma generalizada a todos los bienes mediante un sistema de registro sencillo, el uso de la propiedad con función de garantía ${ }^{4}$ y una mejor situación del acreedor garantizado. Actualmente se habla incluso en algunos países de una cuarta generación de garantías reales mobiliarias relacionada con la atribución de una correspondencia informática a los bienes materiales, que permite que se generen gravámenes a través del uso de la informática (tokenización de activos).

En Uruguay, la Ley de Prenda sin Desplazamiento n. ${ }^{\circ} 17.228$ del año 2000 se ha basado en el modelo anglosajón del security interest, aunque imperfectamente (De Cores, 2008, p. 45). También la Ley Modelo Interamericana sobre Garantías Mobiliarias de la OEA del año 2002, la Reforma del Código Civil Francés del año 2006, ${ }^{5}$ la Ley n. ${ }^{\circ} 119$ de Italia del año 2016; todas las cuales se han encontrado, en general, con dificultades al importar conceptos netamente anglosajones. ${ }^{6}$ No se puede dejar de nombrar asimismo la Ley Modelo de la Cnudmi sobre Garantías Mobiliarias del año 2016 (Naciones Unidas, $2016),{ }^{7}$ que recoge sustancialmente los objetivos y principios de la Guía sobre las Operaciones Garantizadas, el Suplemento sobre la Propiedad Intelectual y la Guía sobre un Registro de la Cnudmi; ${ }^{8}$ todas contienen recomendaciones para el establecimiento de un régimen legal moderno de las operaciones respaldadas con garantías mobiliarias. ${ }^{9}$

\footnotetext{
1 Security es un término amplio que equivale en general a "garantía". Sin embargo, cuando se hace referencia al security interest se alude a un tipo especial de garantía real mobiliaria.

${ }^{2}$ Artículo 2300 del Código Civil: no se admite que el deudor mantenga la posesión del bien.

${ }^{3}$ Prenda agraria, prenda industrial, prenda sobre máquinas.

${ }^{4}$ Fideicomiso en garantía; leasing.

${ }^{5}$ Ordenanza 346 (Francia, 2006, marzo 23).

6 "La falta de familiaridad con un instituto como el security interest ajeno a la tradición latino-continental vigente en Uruguay provocó la confusión del legislador" (De Cores, 2008, p. 238).

${ }^{7}$ El foro en el que la Cnudmi desarrolla su actividad con representación de Estados de diversos sistemas legales ofrece una experiencia única, especialmente relevante para los países del civil law.

${ }^{8}$ El objetivo principal de la ley modelo es promover la concesión de crédito de bajo costo incrementando la oferta de crédito financiero garantizado.

${ }^{9}$ Existe también una guía para la incorporación al derecho interno de la ley modelo de la Cnudmi del año 2017. Disponible en:

https://uncitral.un.org/sites/uncitral.un.org/files/mediadocuments/uncitral/es/guide_to_enactment_of_the_ uncitral_mlst_s.pdf
} 
Este tema refiere a la expansión de las garantías mobiliarias reales como alternativa a las garantías reales sobre bienes inmuebles. Se trata de "poner en el mercado una ingente cantidad de activos que sin duda mejorarán e incentivarán el desarrollo económico" (García-Valdecasas, 2017, p. 359). Se trata en especial de la relevancia de las garantías mobiliarias reales sin desplazamiento:

Este tipo de garantía presenta la gran ventaja de posibilitar al deudor el uso y disfrute de la cosa, y por ende su utilización en el proceso productivo, lo que le permite hacerse de los fondos necesarios para hacer frente a la obligación asumida (Gallino \& Ellerman, 2004, p. 69).

Se intentará comprender en sus grandes líneas el modelo madre del capítulo 9 para impulsar en Uruguay el diálogo e implementar los cambios necesarios en la Ley de Prenda sin Desplazamiento y a nivel registral, ${ }^{10}$ que harían posible seguir la tendencia mundial de preocupación por una adecuada regulación de las garantías mobiliarias. Todo ello a efectos de que las instituciones de intermediación financiera y otros actores crediticios relevantes asuman un papel más protagónico impulsando el crédito y, por ende, la economía.

Se debe tener presente el crecimiento de las garantías mobiliarias sin desplazamiento a nivel internacional, "ya que en la contratación internacional su importancia se ha multiplicado frente a las garantías inmobiliarias por la falta de versatilidad de los bienes inmuebles dentro de una economía moderna y competitiva” (Gallino \& Ellerman, 2004, p. 68).

En el derecho uruguayo se han ido adoptando institutos del derecho anglosajón de acceso al crédito, como el leasing, el factoring y el fideicomiso de garantía; se considera que ha llegado la hora de adoptar también el security interest. ${ }^{11}$ El presente trabajo se trata, por ende, de una propuesta de lege ferenda.

\footnotetext{
10 "Uno de los principales objetivos del capítulo 9 modificado ha sido el de mejorar el funcionamiento de los registros" (Harris \& Mooney, 2016, p. 187).

11 "Se advierte una tendencia en varios países latinoamericanos y aún europeos de importar -aún con variantes de relieve- algunos aspectos del sistema norteamericano de garantías mobiliarias" (De Cores, 2008, p. 16).
} 


\section{Regulación del security interest en el Código de Comercio Uniforme de Estados Unidos de América: capítulo 9}

El Código de Comercio Uniforme ${ }^{12}$ de Estados Unidos (UCC, por su sigla en inglés) surge como un intento de obtener una legislación comercial uniforme aprobada por todos los Estados. Es una ley modelo elaborada por dos organizaciones no gubernamentales: la National Conference of Commissioners in Uniform State Laws y el American Law Institute, presentada luego para su aprobación en los distintos Estados.

El código tiene 11 capítulos. Aquí se centra la atención en el capítulo 9, el cual modificó las normas existentes sobre garantías reales mobiliarias en Estados Unidos de forma sustancial, dejándose de lado las regulaciones específicas que existían hasta el momento, como la prenda, la cesión de crédito, el factoring, englobando a todas dentro de un amplio y único concepto: el security interest (Harris \& Mooney, 2016, pp. 84-85), erigiéndose así el capítulo 9 como paradigma de unificación en materia de garantías.

Este capítulo ha sido revisado y modificado en el año 2010, y ha sido adoptado por todos los Estados, por lo que es derecho positivo en todos los Estados de Estados Unidos (Harris \& Mooney, 2016, p. 86).

\section{Concepto de security interest}

El artículo 1-201 (b) 35 define al security interest como "todo derecho sobre bienes muebles o inmuebles por accesión que garantiza el pago o el cumplimiento de una obligación".

Se podría decir que el security interest es una garantía real sobre bienes muebles que las partes acuerdan voluntariamente de antemano a los efectos de garantizar una obligación, típicamente el pago de un crédito, o el pago del precio de un bien, pero también cualquier tipo de obligación, líquida o no, contingente o no (Harris \& Mooney, 2016, p. 86).

\footnotetext{
${ }^{12}$ Citado en Walt \& Warren (2019): Commercial Law Selected Statutes (2018-2019).
} 


\section{Sujetos en el security interest}

En la terminología del Código de Comercio Uniforme de EE. UU. existen tres sujetos vinculados a las transacciones por las que se crean garantías sobre bienes muebles por acuerdo de partes. Estos son: el deudor u obligado, el dador de la garantía ${ }^{13}$ y el acreedor garantizado. ${ }^{14}$

El dador de la garantía será el propietario de los bienes sobre los que se otorga la garantía y puede no coincidir con el deudor. El acreedor garantizado podrá ser tanto un vendedor, que ha vendido a crédito, como una institución financista, que ha otorgado un préstamo.

\section{Bienes sobre los que se puede constituir la garantía: collateral}

Por collateral se entiende, en general, todos los bienes sobre los que se constituye el derecho real de garantía. Una de las características del security interest es la amplitud de bienes sobre los que se puede constituir, incluyéndose bienes muebles corporales e incorporales, presentes y futuros.

El capítulo 9 tiene la virtud de clasificar dichos bienes en distintas categorías (Cooper, 2000, p. 21) a las que se preocupa por definir a los efectos de dar seguridad al mercado y en función de las cuales existirán diferentes normas a aplicar. Así se podrá constituir un security interest sobre las siguientes categorías:

- cuentas a cobrar (derecho a cobrar las cuentas);

- intangibles que establecen una obligación de pago de dinero;

- títulos valores de contenido dinerario, incluyendo vales y cheques;

- títulos valores representativos de mercadería;

- derechos sobre cartas de crédito;

- acciones de sociedades;

- equipamiento de una empresa, el cual incluye todos los bienes que no sean mercaderías, productos agropecuarios o productos de consumo; ${ }^{15}$

- el inventario o stock de una empresa; ${ }^{16}$

\footnotetext{
${ }^{13}$ Más allá de la acepción normal de debtor (deudor), en sede del security interest, el sujeto denominado debtor puede no ser propiamente el deudor, sino tan solo el dador de la garantía. El deudor en el security interest es denominado obligor (obligado).

${ }^{14}$ Artículo 9-102 (a) puntos 59, 28 y 73.

${ }^{15}$ Artículo 9-102 (33) UCC. En la ley modelo de la Cnudmi: "bien de equipo".

16 "Existencias" en la ley modelo de la Cnudmi.
} 
- derechos sobre contratos de compraventa, leasing o arrendamiento;

- el software cuando se encuentre incluido en un medio propio y separado de otros bienes muebles;

- las cuentas bancarias y otros activos financieros;

- bienes muebles que acceden a inmuebles: fixtures.

Como se verá más adelante, el collateral también incluye a los llamados proceeds sobre dichos bienes dados en garantía; a los que se llama "producido" o "bienes muebles atribuibles" 17 o "producto"; ${ }^{18}$ esto es, los frutos derivados de los bienes originalmente gravados, el producido de su venta y bienes subrogados.

\section{Pasos para constituir un security interest}

El Código de Comercio Uniforme prevé dos etapas para constituir un security interest con plena validez y eficacia entre las partes y frente a terceros: la etapa de attachment y la etapa de perfection.

En caso de que solamente se cumpla con la etapa de attachment, se obtiene un unperfected security interest: derecho real que no ha llegado a su potencial pleno frente a terceros. Por lo tanto, el estatus deseado no es el de secured creditor, sino el de perfected secured creditor.

\section{Attachment: la adherencia del derecho a la cosa}

El attachment ${ }^{19}$ es en sustancia el "acuerdo de garantía" y podría asimilarse a lo que se conoce como el acuerdo de voluntades creador de relaciones personales entre las partes, el negocio obligacional, con algunas diferencias que se desarrollan más adelante; negocio entre las partes sin posibilidad en principio de oponerse a terceros. Se encuentra establecido en el artículo 9-203 y permite lograr una garantía válida y eficaz entre las partes y también frente a algunos terceros (acreedores quirografarios y el comprador que tiene conocimiento de la existencia del security interest). Lleva a la existencia de un secured creditor (Harris \& Mooney, 2016, p. 88).

\footnotetext{
${ }^{17}$ Ley Modelo Interamericana sobre Garantías Mobiliarias.

${ }^{18}$ Ley Modelo de la Cnudmi sobre Garantías Mobiliarias.

${ }^{19}$ Es preciso diferenciar esta etapa de attachment del significado general del término attachment, que es el de embargo o secuestro judicial. En este caso el vocablo attachment refiere a la nota de adherencia del derecho real de garantía.
} 
Tres requisitos son necesarios para cumplir con esta etapa (Harris \& Mooney, 2016): ${ }^{20}$

- Existencia de una contraprestación: el acreedor ha otorgado una contraprestación (un préstamo, un bien por el cual se debe un precio);

- Legitimación para disponer: el dador de la garantía debe ser el propietario de los bienes sobre los que se constituye la garantía o tener la facultad de transferir derechos sobre dichos bienes. Se exige legitimación para disponer, lo que diferencia el attachment de los negocios obligacionales en el derecho uruguayo, en los que no se exige legitimación para disponer (la venta de cosa ajena vale; la legitimación para disponer es requisito de eficacia);

- Acuerdo del dador de la garantía: se obtiene a través de un contrato de garantía (security agreement). El acuerdo del dador de la garantía surge de un documento que: (i) No es necesario que sea extendido por escrito y se encuentre firmado, sino que se establece una exigencia menor: basta que sea auténtico, y para ello el acuerdo del dador de la garantía debe constar en un medio tangible, almacenado y que pueda ser recuperado. El contrato de garantía es válido incluso si consta en un correo electrónico enviado por un representante de la empresa. Véase cuan fácil de obtener es este acuerdo al no requerirse ni documento escrito ni firma. (ii) Establezca claramente la intención del dador de otorgar la garantía. (iii) Puede estar conformado por varios documentos diversos que, en su conjunto, conformen el contrato. (iv) Describa los bienes sobre los que se otorga la garantía en forma "suficiente". Según el artículo 9-108 la descripción es suficiente si "identifica razonablemente" a los bienes; la norma establece ejemplos de identificación razonable, como ser un listado, una categoría. Por otra parte, la descripción no puede ser "super genérica" (por ejemplo "todos los bienes del dador en garantía", "todos los bienes muebles"), sino que debe ser "específica", entendiéndose por especifica establecer, por ejemplo, "todo el inventario", "todas las cuentas a cobrar". Se admite entonces una mayor indeterminación de los bienes al momento de la constitución de la garantía, que en el derecho uruguayo, ya que la ley de Prenda Sin Desplazamiento requiere describir

${ }^{20}$ Artículo 9-203 UCC. 
cada bien, incluyendo todos los datos identificatorios, al referirse a bienes o derechos "concretamente identificables". ${ }^{21}$ Esta mayor indeterminación permite un mayor alcance de este derecho de garantía y mayor agilidad al instituto. (v) Puede incluir "bienes futuros" sin establecerse ninguna limitación al respecto. En el derecho uruguayo también se admite la prenda sobre bienes futuros, pero no en forma tan amplia. (vi) Puede cubrir "deudas futuras".

\section{Perfection: oponibilidad de la garantía mobiliaria ${ }^{22}$}

La etapa de perfection ${ }^{23}$ es la fase externa que facilita a los terceros el conocimiento del gravamen real y torna oponible el derecho real. Se encuentra regulada en los artículos 9-308 a 9-316 y lleva a la existencia de un perfected secured creditor, permitiendo que la garantía se torne oponible a todos los terceros y otorgando prioridad frente a otros acreedores (Harris \& Mooney, 2016, p. 89).

El capítulo 9 regula diferentes formas de obtener oponibilidad, que varían según la naturaleza de los bienes dados en garantía, a saber:

- la anotación en el título;

- el traspaso de la posesión;

- en forma automática;

- el control;

- la inscripción en el registro.

\section{Anotación en el título: automóviles, barcos y casas rodantes}

La propiedad de estos bienes en EE. UU. se transfiere mediante la anotación en el título de propiedad (no se requiere inscripción en un registro); por ende, la publicidad necesaria para tornar oponible a terceros el derecho real se obtiene simplemente mediante la anotación en el título. Dadas las diferentes características del sistema uruguayo en cuanto a publicidad y oponibilidad a terceros, no se ahondará en esta forma de perfection.

\footnotetext{
${ }^{21}$ Artículo 3 de la ley n. ${ }^{\circ}$ 17.228: "Podrá ser objeto de prenda sin desplazamiento todo bien o derecho concretamente identificable".

${ }^{22}$ Etapa relacionada en el capítulo 3 de la ley modelo de la Cnudmi: oponibilidad de una garantía mobiliaria a terceros.

${ }^{23}$ En este caso el vocablo perfection se vincula sustancialmente a la nota de preferencia del derecho real de garantía.
} 


\section{El traspaso de la posesión: artículo 9-313}

Es el caso de los títulos valores, valores negociables corporales incluyendo acciones no escriturales, dinero, todos bienes que se pueden "tocar" y por lo tanto se pueden "poseer" y es posible transferir la posesión de los mismos. En estos casos no se aplica la inscripción en un registro, ya que no sería práctico realizar una búsqueda en el registro cada vez que se acepta este tipo de bienes en garantía.

Es por ello que en estos casos es necesaria la transferencia de la posesión efectiva, para que exista la publicidad necesaria que torne oponible la garantía real. Se requiere la posesión, ya que si estos bienes se mantuvieran en poder del dador de la garantía, quienes contrataran con este no podrían saber si estos bienes están afectados por un security interest (Harris \& Mooney, 2016, p. 208).

La normativa prevé la posibilidad de que se entregue la posesión de dichos bienes directamente al acreedor garantizado, o a un tercero depositario. Este tercero depositario no podrá encontrarse bajo el control del dador de la garantía y deberá suscribir un documento del cual surja que posee estos bienes en custodia para el acreedor garantizado.

La posesión es un medio muy seguro ya que asegura la ejecución forzada en el caso de incumplimiento y no permite que el deudor o el dador de la garantía enajene los bienes.

\section{Constitución automática del derecho real al suscribirse el acuerdo: artículo 9-309}

Es una forma de oponibilidad automática del derecho real, ya que el derecho deviene oponible a terceros al otorgarse el contrato de garantía, nada más es necesario. Esto sucede en algunos casos específica y expresamente detallados en la normativa como excepción al régimen general.

Al respecto solamente se analiza el caso de la Garantía Mobiliaria de Adquisición ${ }^{24}$ en Productos de Consumo (Purchase-Money Security Interest in Consumer Goods), que devendrá oponible a terceros automáticamente, sin trámites ulteriores, si cumple con los siguientes requisitos:

- es una garantía mobiliaria de adquisición: se trata de la garantía mobiliaria que se otorga cuando se obtiene por adelantado el financiamiento necesario para adquirir los bienes sobre los que se otorga la garantía o cuando se vende un bien a crédito;

\footnotetext{
${ }^{24}$ Terminología de la ley modelo interamericana y de la ley modelo de la Cnudmi.
} 
- recae sobre productos de consumo: según se establece en el artículo 9-102, a) 23: "bienes que se compran para uso personal, familiar o doméstico".

Esta oponibilidad automática protege fundamentalmente a quien vende productos de consumo a crédito. La intención es que éste último no incurra en ningún costo transaccional adicional más que el acuerdo de garantía con el dador de la garantía. Desde el momento del acuerdo cuenta con un derecho real de garantía oponible a terceros sobre el producto vendido, por el saldo del precio. Se tutela el interés del vendedor-acreedor por sobre el interés de los terceros (es más factible que el consumidor que compra a crédito no pague a que entregue los productos de consumo en garantía a otros). Ello no significa que no se pueda inscribir en el registro. A veces puede ser prudente inscribirlo, pero no es necesario.

\section{Control: artículos 9-312 b y 9-314}

El control se aplica al caso de garantías mobiliarias sobre cuentas bancarias, cartas de créditos bancarias, documentos electrónicos, activos financieros en general.

En estos casos, según la normativa, el derecho real de garantía solamente puede tornarse oponible a terceros mediante el control; ${ }^{25}$ no corresponde la inscripción en el registro; por lo tanto luego de la firma del contrato de garantía, el security interest deviene oponible simplemente mediante el control. ${ }^{26}$

En el caso de cuentas bancarias, ${ }^{27}$ en general el control lo tendrá la institución financiera en la cual se encuentra la cuenta bancaria. También puede constituirse a favor de otra persona y podrá firmarse un acuerdo con la institución financiera en el cual se establezca que ese tercero tiene el control de la cuenta o establecerse el nombre de ese tercero como titular de la cuenta garantizado. Si el acreedor garantizado no es la institución financiera deberá suscribirse un acuerdo entre acreedor garantizado e institución financiera por el cual esta última acuerde cumplir con las instrucciones del primero (Epstein, Nickles \& Smith, 2003, p. 325).

\footnotetext{
${ }^{25}$ Artículo 9-312(b) (1).

26 "En general los activos financieros no se poseen directamente sino indirectamente a través de instituciones, ya se trate de bancos o de intermediarios financieros, por lo que el artículo 9 teniendo bien presente esa peculiaridad, la ha focalizado para regular con propiedad lo relativo a los derechos reales sobre activos financieros" (De Cores, 2008, p. 165).

${ }^{27}$ En el caso de depósitos bancarios, en el derecho uruguayo, la institución de intermediación financiera se transforma en propietaria del dinero depositado y el depositante tiene únicamente un derecho de crédito frente a la institución financiera. Por ende, en realidad, la institución financiera no solo tiene el control del depósito bancario sino también la propiedad de los fondos depositados. En este caso la garantía real entonces será sobre el derecho de crédito del titular de la cuenta.
} 
Esta situación engloba el caso de quien tiene fondos depositados en una institución de intermediación financiera y necesita liquidez; la institución adelanta fondos a su cliente sin necesidad de que este renuncie a su depósito y la misma queda amparada por este derecho real de garantía y la seguridad y oponibilidad que le otorga el control de la cuenta bancaria (De Cores, 2008, p. 173).

El pragmatismo del derecho anglosajón prescinde en estos casos de la necesidad de otro requisito más que el del control de la cuenta bancaria y evita costos adicionales.

\section{El régimen general: la inscripción en el registro: artículo 9-310}

El artículo 9-310 establece la regla general: salvo que se establezca lo contrario la garantía mobiliaria deviene oponible a terceros mediante el registro de un financing statement: al que se denominará declaración de financiamiento, formulario de inscripción registral $^{28}$ o notificación inicial. ${ }^{29}$

El formulario de inscripción registral es un documento esquelético con información sumaria (De Cores, 2008, p. 155), que no incluye el contrato de garantía; es similar a una ficha registral y se inscribe de forma electrónica, en la Oficina de la Secretaría de Estado, del domicilio del dador de la garantía. Se registra por el nombre del dador de la garantía, esto es, el propietario de los bienes, ${ }^{30}$ estableciéndose el día y la hora. Se trata de una inscripción facultativa, un imperativo del propio interés, ya que el interesado obtiene a través de esta inscripción la oponibilidad frente a terceros. ${ }^{31}$

Cualquier interesado podrá obtener, vía electrónica, la información al respecto, buscando por el nombre del dador de la garantía (el propietario de los bienes), pagando una tasa.

\section{¿Qué información debe contener el formulario de inscripción registral?}

El artículo 9-502 A establece los requisitos necesarios:

- El nombre del dador de la garantía,

- El domicilio del dador de la garantía,

\footnotetext{
${ }^{28}$ En la terminología de la ley modelo interamericana.

${ }^{29}$ Ley modelo de la Cnudmi.

${ }^{30}$ Registro de base personal, subjetiva.

${ }^{31}$ El derecho real existe entre las partes desde el attachment, pero deviene oponible a terceros a partir de la inscripción. Es un sistema de publicidad declarativa tal como el establecido por nuestra Ley de Prenda sin Desplazamiento, a diferencia del sistema de la prenda común del Código Civil el cual establece una publicidad constitutiva del derecho real (Wonsiak \& Curbelo, 2000, p. 8).
} 
- El nombre del acreedor garantizado,

- La indicación de los bienes alcanzados por la garantía.

No es necesario incluir:

- El monto por el cual se constituye la garantía,

- La razón por la cual se constituye la garantía.

Con respecto al nombre del dador de la garantía, es un sistema flexible; los errores menores son admitidos; esto es, el formulario de inscripción registral es siempre válido y eficaz salvo si el error en el nombre es "gravemente engañoso".

En cuanto a los bienes dados en garantía, se exige una simple "indicación"; ya no se exige una "descripción suficiente" y "razonable" como se exige en el caso del contrato de garantía. ${ }^{32}$ En el formulario de inscripción registral basta con una "indicación" de los bienes. Luego el interesado podrá solicitar al dador de la garantía o al acreedor garantizado, el contrato de garantía para analizar específicamente los bienes alcanzados. También se admiten las indicaciones genéricas. Es suficiente con decir "algunos automóviles" o "todos los activos".

No es necesaria la firma del dador de la garantía en el formulario de inscripción registral, solo su autorización; a dichos efectos el otorgamiento del contrato de garantía, se considera suficiente autorización para la inscripción. Ello permite inscribir el formulario electrónicamente.

La experiencia estadounidense (con anterioridad se exigía la firma del dador de la garantía) ha demostrado que ello no ha llevado a un aumento de registros fraudulentos. De todas formas, en caso de formularios de inscripción registral falsos o incorrectos, la persona involucrada podrá inscribir (artículo 9-518) un formulario de información señalando que el formulario de inscripción registral es falso o incorrecto. Cualquier interesado verá entonces dos inscripciones diferentes y deberá profundizar en el tema para determinar la realidad subyacente.

${ }^{32}$ Sin embargo, la ley modelo de la Cnudmi exige una descripción de los bienes que "permita razonablemente identificarlos", capítulo 4, artículo 28(11). 
El artículo 9-513 se refiere al formulario de cancelación. ${ }^{33}$ En el caso de que se pague la totalidad del monto adeudado, el acreedor garantizado deberá inscribir un formulario de cancelación, dentro de los siguientes 20 días a la solicitud del dador de la garantía. No se inscribe en forma automática; se requiere la solicitud del dador de la garantía; la razón para ello es que puede existir interés de ambas partes en mantener el formulario de inscripción registral vigente para un préstamo subsiguiente, de acuerdo a lo que se verá a continuación. ${ }^{34}$

El formulario de inscripción registral inscripto tendrá una validez de cinco años; ${ }^{35} \mathrm{se}$ podrá inscribir un formulario de prórroga, el cual solamente podrá inscribirse en los últimos seis meses antes de cumplirse el término de cinco años.

El notice filing (De Cores, 2008, p. 236) es un concepto novedoso, es una inscripción que servirá únicamente para dar aviso. Es por ello que se requiere tan poca información a quien realiza la inscripción; no es necesario realizar una descripción de los bienes sino que basta con la indicación de los mismos. La persona que consulta el registro recibe un aviso, una noticia, de que existe un contrato de garantía otorgado o por otorgarse; luego la persona deberá solicitar información, obtener ese contrato y analizarlo. Es recién en el contrato donde se encuentra la descripción suficiente de los bienes dados en garantía; aquellos bienes que no se encuentren descriptos adecuadamente en el contrato de garantía no quedarán alcanzados por la garantía.

La ley modelo de la Cnudmi ha recogido este concepto de simple aviso y es por ello que denomina a este formulario de inscripción, "notificación inicial". ${ }^{36}$

Cabe destacar que, según establece el artículo 9-502 E, el formulario se puede inscribir antes de que se cumpla con la etapa del attachment previamente descripta; funciona en cierto sentido como una reserva de prioridad, siendo esta la práctica recomendable (inscribir el formulario de inscripción registral mientras se negocian los documentos del contrato de garantía y el contrato de préstamo), la fecha de la inscripción del formulario de inscripción registral será la fecha que se tendrá en cuenta a los efectos de las reglas de prioridad.

\footnotetext{
${ }^{33}$ Notificación de cancelación en la ley modelo de la Cnudmi.

34 "El notice filing ha demostrado ser muy útil en financiamiento de inventario, cuentas a cobrar, desde que elimina la necesidad de volver a inscribir en una relación financiera de crédito, cuando los bienes prendados cambian permanentemente" (De Cores, 2008, p. 145).

${ }^{35}$ Plazo de caducidad, sujeto a reinscripción. Véase la similitud con el plazo de caducidad previsto para la prenda sin desplazamiento en el artículo $79,1.6$ de la ley n. ${ }^{\circ} 16.871$.

${ }^{36}$ Capítulo 4, artículo 28, A(1): "Por Notificación Inicial se entenderá toda notificación que se presente al registro, en el formulario de notificación establecido con el fin de que la garantía mobiliaria a que se refiere este notificación sea oponible a terceros".
} 
Luego de esta inscripción inicial, no es necesario inscribir el contrato de garantía, como si es necesario en Uruguay cuando se inscribe previamente una reserva de prioridad; en el régimen del capítulo 9 basta con la inscripción inicial del formulario que da aviso de la existencia de una garantía. Es por lo tanto una reserva de prioridad diferente a la prevista por la ley uruguaya, ya que luego no se ingresa un documento ulterior al registro; simplemente se firma el contrato de garantía entre las partes y el mismo adquiere la prioridad dada por dicha reserva, sistema por ende mucho más sencillo.

Se establecen muy pocas posibilidades de rechazo de la inscripción del formulario de información registral y existen formularios ya aprobados, utilizando los cuales se realiza la inscripción sin posibilidad de observaciones por parte del registro (Harris \& Mooney, 2016, p. 188).

En definitiva, es un sistema de registro sencillo, abreviado y con poca información, lo que da agilidad al ingreso de los formularios, a la consulta y al otorgamiento del crédito.

\section{Bienes atribuibles o producido de los bienes dados en garantía: artículo 9-315}

El artículo 9-102 (a) 64 define a los proceeds como todo lo que se adquiera como contraprestación por la venta, arrendamiento o licencia, permuta u otra forma de enajenación de los bienes dados en garantía. Es todo aquello que se adquiere y sustituye a los bienes en garantía iniciales, que han sido enajenados o reducidos en su valor.

Tal como surge del artículo 9-315, se prevé la continuidad del derecho real de garantía sobre un bien, en el producido ${ }^{37}$ de ese bien. El derecho real de garantía constituido sobre un bien mueble se extiende también automáticamente al producido de tal bien, salvo en algunos casos específicos (artículo 9-203(f))..$^{38}$

Resalta el contraste entre este amplio concepto y el de los frutos de los bienes o derechos prendados (inciso tercero del artículo 3 de la Ley de Prenda sin Desplazamiento) o el de bienes que ingresen al patrimonio del dador sustituyendo o complementando, los cuales deben encontrarse en el mismo lugar físico, mediando adicionalmente pacto expreso (inciso segundo del artículo 3 de dicha ley).

\footnotetext{
${ }^{37}$ Artículo 3 de la ley modelo interamericana: "Bienes Muebles Atribuibles: los bienes muebles que se puedan identificar como derivados de los originalmente gravados, tales como los frutos que resulten de su venta, transformación o sustitución".

${ }^{38}$ Artículo 9-203 (f): "La etapa del attachment del security interest sobre determinados bienes le otorga al acreedor garantizado el mismo derecho sobre el producido de estos bienes según lo establece el artículo 9$315 "$.
} 
En el caso de instituciones financistas que se vinculan a largo plazo con deudores, es absolutamente necesario que el security interest que se ha otorgado sobre el inventario se extienda al producido del mismo cuando este inventario se vende; las instituciones financistas ya saben que ese inventario se va a vender y por lo tanto deben cubrirse con el producido de dichas ventas.

Lo mismo sucede en el caso de cuentas a cobrar sobre las que se constituye un security interest, la institución financista ya sabe que dichas cuentas a cobrar se cobrarán efectivamente, por lo que el security interest debe cubrir también ese producido (Harris \& Mooney, 2016, p. 225).

En el caso de otorgamiento de un security interest sobre equipamiento, ese equipamiento no debería venderse; sin embargo si el dador de la garantía vende ese bien contraviniendo sus obligaciones, el acreedor se encontrará protegido ya que el security interest se mantendrá vigente en el producido de esa venta.

Puede suceder que el producido de un bien dado en garantía ya se encuentre cubierto por el contrato de garantía, no como producido, sino como otro bien mueble alcanzado por el contrato de garantía. Esto es así cuando se pacta que el derecho real de garantía alcanzará al inventario y a las cuentas a cobrar y a los cheques y vales. El inventario se transformará ya sea en cuentas a cobrar, en cheques, vales, y de esta forma esas cuentas a cobrar, cheques y vales quedan alcanzados por la garantía original. Asimismo, si en el contrato de garantía se establece que el mismo alcanza al inventario actual y futuro, quedan cubiertos los casos en que pueda existir una permuta, por ejemplo. Solamente en el caso de que no estuvieran cubiertos por la garantía original se recurre a la figura del producido o bien atribuible. Los bienes atribuibles podrán consistir en dinero o bienes muebles que no sean dinero.

El tema adquiere mayor importancia en caso de concurso o quiebra del dador de la garantía, ya que el producido no alcanzado por el security interest y obtenido luego del concurso o quiebra quedaría fuera de la protección de la garantía real; por el contrario, el producido alcanzado por el security interest queda a salvo del concurso o quiebra. 


\section{Producido en dinero}

Cuando el deudor vende el bien sobre el cual recae un security interest y obtiene por tal bien dinero, el security interest se mantiene vigente en dicho dinero. Ese dinero debe ser "identificable" y no ser utilizado por el deudor. Una vez que ese dinero se utiliza para pagar alguna otra cosa, el dinero se transferirá libremente ${ }^{39}$ y el security interest dejará de alcanzarlo.

¿Cuándo se puede hablar de producido en dinero "identificable"? 40

Se aplican las llamadas tracing rules (reglas de trazabilidad) esto es reglas de seguimiento del dinero para evitar su confusión con otros dineros del deudor. Estas reglas fueron desarrolladas por el precedente judicial y estaban originalmente orientadas a ser aplicadas en el caso de apropiación y uso indebido del dinero por parte del fiduciario del dinero del fideicomiso que administra (Harris \& Mooney, 2016, p. 243).

\section{Reglas de prioridad: artículos 9-317 al 9-340}

Si bien la prioridad no es absoluta, es el alma de la garantía real mobiliaria

De Cores, 2008, p. 177.

La primera regla a considerar es que el acreedor garantizado que ha obtenido la oponibilidad frente a terceros, tendrá mejor derecho frente a otro acreedor que solamente ha celebrado la primera etapa de constitución del derecho (el attachment), pero no ha logrado la oponibilidad del derecho real. ${ }^{41}$

Entre dos acreedores garantizados que hayan logrado obtener oponibilidad frente a terceros, la regla que surge del artículo 9-322, es la siguiente: el primero en obtener la oponibilidad tiene mejor derecho, pero el que primero ingresa al registro es el que prefiere. ${ }^{42}$

\footnotetext{
${ }^{39}$ El dinero se transfiere free and clear, esto es, nadie debe verificar de donde proviene ese dinero y si está alcanzado por un derecho real; quien toma ese dinero lo toma sin gravamen alguno. De lo contrario, se interrumpiría el tráfico de dinero.

${ }^{40}$ Artículo 9-315 (b) 2.

${ }^{41}$ Artículo 9-322 2.

${ }^{42}$ First to file or perfect Rule.
} 
Se debe recordar que hay casos que la oponibilidad se adquiere sin necesidad de inscripción alguna en el registro y en ese caso se aplicará la regla de que el primero en obtener la oponibilidad prefiere. Para los casos de inscripción registral se aplica el Principio de Prioridad, ${ }^{43}$ por el cual:

El acto registrable que primeramente ingresa en el registro de la propiedad se antepone con preferencia excluyente o superioridad de rango a cualquier otro acto registrable que siéndole incompatible o perjudicial, no hubiere ingresado aún en el registro, aunque fuese de fecha anterior (Roca Sastre, 1968, p. 148).

Es preciso tener en cuenta que el formulario de inscripción registral puede inscribirse antes de otorgarse el préstamo y de firmarse el contrato de garantía como ya se ha señalado. En ese caso, al momento de inscribirse el formulario, la garantía no deviene aún oponible porque el contrato no se ha firmado; devendrá oponible en un momento posterior, al firmarse el contrato (attachment) y quizás exista otro acreedor, cuyo security interest devenga oponible antes, pero al estar ingresado con anterioridad el formulario de inscripción registral, este contrato de garantía firmado en un momento posterior adquiere la prioridad dada por la fecha de ingreso del formulario de inscripción registral (Harris \& Mooney, 2016, p. 250).

\section{¿Qué sucede entre al derecho del acreedor garantizado y el comprador de buena}

\section{fe de esos bienes dados en garantía?}

La regla general es que el derecho real de garantía sobrevive luego de la venta de los bienes, no solo en los bienes sino también en su producido ${ }^{44}$ y es oponible también a los cesionarios y acreedores del comprador durante el plazo de vigencia de la garantía, aun cuando la inscripción se encuentre a nombre del antiguo titular. Se está en presencia del derecho de persecución o inherencia del derecho real (artículo 9-201).

Y es más, según el artículo 9-323 d si se otorgaran nuevos préstamos basados en la garantía de estos bienes, hasta 45 días ${ }^{45}$ luego de su venta y el acreedor no tuviera conocimiento de la venta de dichos bienes, la garantía otorgada alcanzará también a estos nuevos préstamos, aunque los bienes hayan sido vendidos y no sean más de propiedad

\footnotetext{
${ }^{43}$ Artículo 59 de la Ley n. ${ }^{\circ} 16.871$.

${ }^{44}$ Artículo 9-315 (a) 2.

${ }^{45}$ Se trata de un período de gracia (establecido en base a razones fiscales) otorgado al acreedor garantizado, para que pueda conocer la venta.
} 
del dador de la garantía. Recién luego de los 45 días de la venta de los bienes afectados, la garantía pierde vigencia para nuevos préstamos, tutelándose al comprador.

Existen dos excepciones que tutelan al comprador de buena fe (artículos 9-315 y 9$320)^{46}$

- En el caso de que el acreedor garantizado haya autorizado al dador de la garantía a vender los bienes, la garantía pierde vigencia; ${ }^{47}$

- Si además de ser un comprador de buena fe es un comprador que adquiere los bienes en el curso ordinario de los negocios del vendedor (buyer in the ordinary course of business), este adquiere el bien libre de la garantía.

El comprador en el curso ordinario de los negocios del vendedor o del dador de la garantía es aquel que compra un bien al dador de la garantía y que debe cumplir con ciertas características (artículo 1-201 b 9): i) debe ser un comprador; ii) que compra bienes; iii) de un comerciante (una persona que vende productos de este tipo); iv) en el curso ordinario de los negocios de dicho comerciante; v) que no sabe que el vendedor no puede vender y por lo tanto se trata de un comprador de buena fe; ${ }^{48}$ vi) que toma posesión del bien; vii) que no adquiere los bienes en pago de una deuda.

El comprador en el curso ordinario de los negocios es tutelado por la norma, ya que este no puede investigar cada vez que compra un bien en el curso ordinario de los negocios de un comerciante si quien vende se encuentra legitimado para hacerlo. "El adquirente que de acuerdo con el principio romano de legitimidad de que nadie puede adquirir más derechos de los que tiene debería adquirir los bienes gravados, sin embargo los adquiere libres de todo derecho real menor de garantía" (De Cores, 2008, p. 177).

Y ello porque ningún comprador va a estar solicitando información al registro para verificar si existe un gravamen sobre el bien que desea comprar en un comercio. Este comprador se encuentra protegido por la norma, la cual no establece como requisito que sea un consumidor.

La ley uruguaya de prenda sin desplazamiento, no ha recibido este concepto y por lo tanto como señala De Cores: "El legislador uruguayo ha recibido la idea de las garantías mobiliarias de la tercera generación, pero dejó sin resolver la principal cuestión:

\footnotetext{
${ }^{46}$ Estas mismas excepciones han sido recogidas en la ley modelo de la Cnudmi, artículo 34.

${ }^{47}$ Artículo 9-315(a)1.

${ }^{48}$ El concepto de comprador de buena fe es más amplio que el de comprador en el curso ordinario de los negocios.
} 
protección del adquirente en el curso normal de los negocios" (2008, p. 245). Ello es hoy un obstáculo que debería solucionarse para lograr una aplicación más efectiva de estas garantías mobiliarias.

\section{Excepciones al régimen general de prioridad: super prioridades}

Existen algunas excepciones al régimen general de prioridad. En el presente se analiza únicamente el caso de la llamada garantía mobiliaria de adquisición. Existen dos tipos de garantía mobiliaria de adquisición (Purchase-Money Security Interest; PMSI) según la definición del artículo 9-103:

- la que tiene el vendedor para garantizar una obligación de pago del precio de compra de los bienes dados en garantía: es el caso de venta a crédito con un security interest por el saldo de precio (artículo 9-324 (g));

- la que tiene una institución financista para garantizar la obligación de pago por un adelanto otorgado al deudor para adquirir los bienes dados en garantía. Se exige que el dinero sea entregado efectivamente como adelanto y que el mismo se utilice efectivamente para adquirir esos bienes. En general, para asegurarse de que ello es así, la institución financista paga directamente al vendedor de los bienes.

Según establece el artículo 9-324, una garantía mobiliaria de adquisición prima frente a una garantía mobiliaria que no es de adquisición. El PMSI da lugar a la existencia de un régimen de prioridad especial aun cuando este security interest se hubiera inscripto o se hubiera tornado oponible en una fecha posterior a un security interest que no constituye una garantía mobiliaria de adquisición, siempre que se cumplan los requisitos estipulados en el artículo 9-324, ${ }^{49}$ el cual estipula diferentes requisitos según la categoría de activos involucrados.

La razón de ser de esta protección especial al PMSI es la de evitar la situación de monopolio de la institución financiera que hubiera inscripto un formulario de inscripción registral incluyendo la cláusula de que se aplica también a bienes adquiridos en el futuro. De esta manera el titular de los bienes puede obtener una financiación adicional de otra persona o institución para adquirir otros bienes, deja de depender de la primera institución

\footnotetext{
${ }^{49}$ Obtención de la oponibilidad de la garantía al momento de la posesión o dentro de un período de gracia, notificación por escrito a las partes posiblemente afectadas en un determinado plazo para el caso de inventario, entre otros.
} 
financista y tiene libertad para negociar otro préstamo con otra institución, que quedará garantizado con los bienes para cuya adquisición se otorga el préstamo. Además, la institución financista que ha inscripto con anterioridad el formulario de inscripción registral no se verá perjudicada, ya que se trata de un nuevo activo que adquiere su deudor y ello por ende no afecta la situación del primero (Harris \& Mooney, 2016, p. 273).

\section{Concurso o quiebra del dador de la garantía (el titular de los bienes)}

La situación de concurso o quiebra se encuentra regulada por la ley federal de quiebra y concursos, en aplicación del capítulo 1, artículo 8 de la constitución, la cual se aplica a todos los Estados de los Estados Unidos (Epstein, Nickles \& Smith, 2003, p. 331).

El capítulo 7 de la misma regula el concepto tradicional de quiebra: cesación de actividades del deudor, liquidación de todos los bienes y pago de las deudas a prorrata; mientras que el capítulo 11 se vincula al proceso concursal. La solicitud de declaración de la quiebra produce la suspensión de todos los procesos contra el deudor, nombrándose un síndico, el cual deberá vender los activos y luego distribuir el dinero entre los acreedores (Harris \& Mooney, 2016, p. 457).

Sin embargo, el acreedor que cuente con la garantía real que se está analizando podrá cobrar el $100 \%$ de la deuda de los bienes alcanzados por dicha garantía. En caso de determinar que existe un security interest, el acreedor con garantía real ejecutará la garantía en forma independiente, contando luego con un crédito quirografario por la porción de la deuda que no haya quedado cubierta.

De todas formas, el síndico tendrá prioridad frente al acreedor que ha suscrito un acuerdo de garantía pero que no ha completado el proceso para obtener una garantía oponible a terceros; el síndico también podrá revocar un security interest en los casos establecidos en los artículos 544 y 547 de la ley de quiebras y concursos, security interests otorgados dentro del período de los 90 días anteriores a la declaración del concurso o quiebra que han permitido a un acreedor una situación privilegiada frente a otros acreedores, con algunas excepciones. ${ }^{50}$

\footnotetext{
${ }^{50}$ Regulación similar a la del art. 81 de la ley n. ${ }^{\circ} 18.387$.
} 


\section{Incumplimiento y ejecución de la garantía: capítulo 9, parte 6}

Este capítulo establece normas de orden público que no podrán ser modificadas por acuerdo de partes según establece el artículo 9-602:

La Parte 6 del Capítulo 9 se aparta del énfasis general que el UCC realiza del principio de la autonomía de la voluntad. [...] La Parte 6 contiene normas que no pueden renunciarse ni pueden ser modificadas, ni aún por dadores de la garantía sofisticados, asesorados por abogados (Harris \& Mooney, 2016, p. 578).

\section{Tomar posesión de los bienes dados en garantía: aprehender los bienes}

Según el artículo 9-609, en caso de incumplimiento del deudor, ${ }^{51}$ se permite al acreedor garantizado tomar posesión de los bienes dados en garantía o dejar esos bienes inutilizables para el deudor. ${ }^{52}$ Podrá hacerlo:

- Extrajudicialmente: ${ }^{53}$ siempre y cuando no se afecte la paz (breach of peace; Harris \& Mooney, 2016, p. 584), en cuyo caso el acreedor incurriría en daños y perjuicios. Se ha discutido mucho sobre el significado de breach of peace y en la última revisión del UCC se intentó incluir una lista de situaciones en dicho concepto. Sin embargo, los codificadores han preferido mantener este concepto amplio, a los efectos de que las situaciones sean determinadas judicialmente en cada caso concreto. ${ }^{54}$ Ello presenta varios riesgos para el acreedor, ya que puede enfrentar demandas por daños y perjuicios; por ello esta vía extrajudicial se aplica fundamentalmente solo para el caso de automóviles que se encuentran en la vía pública.

\footnotetext{
${ }^{51}$ El capítulo 9 no define el incumplimiento por lo que determinar cuando existe incumplimiento puede tornarse una tarea difícil para los jueces y debería ser adecuadamente definido en el contrato de garantía para evitar problemas (Harris \& Mooney, 2016, p. 580).

52 "Es clave recordar que en el derecho del common law la garantía real nunca dejó de consistir, en sustancia, en una transferencia, de modo que la cosa, está más bien en el patrimonio del acreedor, aunque el deudor mantenga su simple tenencia" (De Cores, 2008, p. 180).

${ }^{53}$ En el derecho uruguayo, la posibilidad de cobro directo en el caso de la cesión de créditos en garantía es también una forma de aprehensión extrajudicial del bien.

${ }^{54}$ En general se entiende que no es posible ingresar al hogar ni al garaje, ni a algún lugar en el que existe un cartel de propiedad privada, no es posible retirar el bien si el dador de la garantía conoce la situación y se opone a perder la posesión aún en forma verbal; no es posible utilizar el auxilio de la fuerza pública para generar miedo o amenaza.
} 
- Judicialmente: para evitar el problema de afectación de la paz y una posible demanda por daños y perjuicios, en general se utiliza la vía judicial. El proceso judicial $^{55}$ aplicable es de todas formas sumamente sencillo y ágil ya que basta con presentar la constancia de la existencia del security interest y del incumplimiento y el juez cita al dador de la garantía a una audiencia entre los siguientes tres a siete días. En caso de incomparecencia del dador de la garantía el acreedor presenta una declaración jurada y constituye contracautela mediante una póliza de seguro por el doble del valor de los bienes que constituyen la garantía; luego el juez ordena la restitución del bien y se procede al secuestro.

\section{Enajenación de los bienes, artículo 9-610}

El acreedor que ha obtenido la aprehensión de los bienes dados en garantía puede luego venderlos, arrendarlos o de otra manera enajenar los bienes, sin intervención judicial alguna, ya sea a través de una venta directa o mediante remate, pero debiendo notificar con diez días de antelación ${ }^{56}$ a cualquiera que pudiera tener un interés en dichos bienes (fiadores, todo titular de derecho inscripto, cualquier interesado); cada una de estas personas tendrá derecho a rescatar los bienes, pagando su valor. ${ }^{57}$

Asimismo, la enajenación debe realizarse en forma "comercialmente razonable" (artículo 9-610 b). ¿Qué significa comercialmente razonable? Este concepto subjetivo apela nuevamente al principio de la razonabilidad que lleva a que lo comercialmente razonable se convierta en una cuestión de hecho a analizarse caso a caso considerando los parámetros establecidos en el artículo 9-627: de la forma usual en la que se realizaría en cualquier mercado reconocido; al precio normal que se maneja en cualquier mercado reconocido; de acuerdo con prácticas comerciales usuales.

El concepto subyacente es el de que el acreedor garantizado debe enajenar el bien, ya sea mediante remate público o venta privada, de la forma que lo habría hecho si no se tratara de un bien sujeto a una garantía mobiliaria. De igual manera, en caso de venta a personas vinculadas de alguna forma al acreedor garantizado, el artículo 9-615 establece una regla especial en cuanto a que el precio deberá ser el mismo que se hubiera obtenido si la venta hubiera sido realizada a un tercero cualquiera (Harris \& Mooney, 2016, p. 638).

\footnotetext{
${ }^{55}$ Replein Action: acción reivindicatoria. Véanse los artículos 686, 691 y 692 del Código Civil y el artículo 309.2 del Código General del Proceso.

${ }^{56}$ Artículo 9-612.

${ }^{57}$ Artículo 9-611.
} 
En el caso de que el dador de la garantía se encuentre en quiebra o concurso, aun cuando la venta se realiza sin intervención ni control judicial, y aun cuando el síndico no interviene de forma alguna en la misma, deberá solicitarse luego de la venta, la aprobación del juez de concursos y quiebras el cual deberá analizar si efectivamente se trata de una venta realizada en forma comercialmente razonable.

Aún en el caso de que la venta no hubiera sido realizada en forma comercialmente razonable, el comprador de buena fe siempre adquiere el bien libre de todo gravamen y el asunto deberá dilucidarse entre el acreedor garantizado y el dador de la garantía. La realidad es que raramente los bienes en garantía son suficientes para cubrir la totalidad de la deuda y normalmente el acreedor garantizado deberá iniciar una acción por el remanente para recuperar el saldo restante; será en esta instancia que el dador de la garantía argumentará que la venta no fue realizada en condiciones comercialmente razonables; en este caso la carga de la prueba en cuanto a la razonabilidad comercial de la venta será del acreedor garantizado.

El dador de la garantía, por su parte, tendrá siempre la posibilidad de rescatar los bienes, pagando el total adeudado. ${ }^{58}$

Asimismo, el acreedor garantizado puede adjudicarse en pago total o parcial los bienes directamente siempre que, tal como estipula el artículo 9-620, el dador de la garantía lo acepte ${ }^{59}$ y el acreedor garantizado no reciba una notificación de oposición de parte de las personas interesadas en dichos bienes, como pueden ser otros acreedores garantizados por los mismos bienes. ${ }^{60}$

\section{Alcance del capítulo 9: artículo 9-109}

El capítulo 9 analizado no solo se aplica a las transacciones por las cuales se crean derechos reales de garantía sobre bienes muebles, sino también a otras transacciones.

\footnotetext{
${ }^{58}$ Artículo 9-623.

${ }^{59}$ En caso de que con la adjudicación se satisfaga parcialmente la deuda se requiere aceptación expresa del dador de la garantía; en caso de que se satisfaga la deuda en su totalidad, se entenderá que existe aceptación del dador de la garantía si este no se opusiera dentro del plazo de 20 días de conocida la propuesta dándose relevancia al silencio del dador de la garantía.

${ }^{60}$ Esto no es posible en la actual ley uruguaya de prenda por la prohibición del pacto comisorio en los negocios de garantía.
} 


\section{Alcance básico}

Según establece el artículo 9-109, el capítulo 9 se aplica a: toda transacción que "sin importar su forma", ${ }^{61}$ crea un security interest sobre bienes muebles o muebles que acceden a inmuebles (fixtures), por acuerdo de partes. El artículo 2 de la ley modelo de la Cnudmi también establece la aplicabilidad a todo acuerdo de garantía más allá del nombre empleado por las partes. ${ }^{62}$ En ambos es la sustancia del acuerdo subyacente y no su nombre lo relevante. ${ }^{63}$

\section{Alcance extendido}

Existen otras situaciones que también quedan incluidas en el capítulo 9, que no configuran transacciones por las que se crean garantías reales sobre bienes muebles per se, que serán tratadas como tales. Este es el caso de la venta de cuentas a cobrar, venta de intangibles que establecen la obligación de pago de dinero y de vales; las consignaciones (artículo 9-102a)20); ${ }^{64}$ y ciertos arrendamientos que en realidad configuran ventas disfrazadas. ${ }^{65}$ En todos estos casos a los efectos de que el comprador, el consignante o el arrendador se encuentren protegidos deberán cumplir con las disposiciones del capítulo 9; esto es, básicamente deberán inscribir un formulario de inscripción registral.

\footnotetext{
61 "La forma de la operación o el nombre que le den las partes es irrelevante para determinar si aplica o no el capítulo 9. La determinación se realiza en base a la realidad económica subyacente" (Cooper, 2000, p. 19).

62 "Todo derecho creado de común acuerdo sobre cualquier tipo de bien mueble con el fin de garantizar el pago u otra forma de cumplimiento de una obligación se considera una garantía mobiliaria a los efectos de la aplicación de la ley modelo, independientemente de los términos que hayan utilizado las partes para describir el acuerdo celebrado entre ellas (por ejemplo, prenda, gravamen, transmisión de la titularidad con fines de garantía, compraventa con reserva de dominio o arrendamiento financiero" (Naciones Unidas, 2012).

63 "El artículo 9 del Código de Comercio Uniforme (UCC) establece el principio de que cualquiera sea la forma, si el contenido económico de la operación es establecer una garantía, la situación se rige por el artículo 9" (De Cores, 2008, p. 140).

${ }^{64}$ Según el artículo 9-102 a) 20, las consignaciones con transacciones por la cuales, sin importar su forma una persona entrega bienes a un comerciante, que vende bienes de este tipo, que no es un rematador, al cual no se conoce en general por vender bienes de otra persona y los bienes no son bienes de consumo antes de la entrega.

${ }^{65}$ Cuando el arrendamiento desde el punto de vista económico implique una venta en cuotas y la creación de un derecho real de garantía a favor del arrendador por el pago del precio. El artículo 1-203 establece las pautas que permitirán al intérprete distinguir entre un "verdadero arrendamiento" y un "arrendamiento disfrazado".
} 


\section{La regulación uruguaya a la luz de la moderna tendencia en garantías mobiliarias}

La Ley de Prenda sin Desplazamiento n. ${ }^{\circ} 17.228$, del año 2000, tuvo en su momento una gran importancia al regular en un único texto la prenda sin desplazamiento con carácter general, ${ }^{66}$ permitiendo que la cosa permanezca en poder del deudor, el cual conserva la tenencia de la cosa en nombre del acreedor y con las responsabilidades del depositario. Reguló, asimismo, la prenda flotante sobre bienes fungibles, estableció un sistema de ejecución más rápido y estableció un sistema de publicidad declarativa, entre otros aspectos.

Sin embargo, al día de hoy, y a la luz del modelo del derecho anglosajón analizado, así como de las sucesivas leyes que se han venido gestando, la misma presenta algunas limitaciones, a saber:

- No da expresa cabida al principio de autonomía de la voluntad para que las partes puedan en forma flexible utilizar en forma amplia la propiedad con función de garantía, a pesar de recogerse el principio de autonomía de la voluntad en algunos artículos ("salvo pacto en contrario", "podrá pactarse expresamente", etc.), a diferencia del UCC que acoge expresamente el principio de la autonomía de la voluntad (artículo 1-302) como también lo hace la ley modelo de la Cnudmi (artículo 3). ${ }^{67}$

- En su artículo 3, a pesar de que la enumeración realizada no es taxativa, se requiere que los bienes sean "concretamente identificables," 68 lo que puede llevar a que el registrador se pregunte si el bien en cuestión es concretamente identificable o no, limitando de esta forma el elenco de bienes a los que se puede aplicar la garantía mobiliaria, debiendo haberse establecido que se puede constituir sobre cualquier bien susceptible de valoración pecuniaria, ya que lo que importa es el valor del bien. ${ }^{69}$

\footnotetext{
66 "El artículo 2 de la ley n. ${ }^{\circ} 17.228$ legitima que la cosa objeto de la prenda permanezca en poder del dador" (Groisman, 2019, p. 827).

${ }^{67}$ De todas formas, en este ámbito deben necesariamente existir normas de orden público para la protección de terceros.

${ }^{68} \mathrm{La}$ doctrina es conteste en cuanto a las dificultades que plantea este artículo 3 (de Cores, 2002, p. 85).

69 'A A mi entender hay un único freno en esta ley y es el 'concretamente identificable'. ¿Hasta dónde puedo, respecto de una herramienta futura que no está hoy en mi patrimonio, decir que es 'concretamente identificable'?" (Wonsiak \& Curbelo, 2000, p 26).
} 
- Además, esta exigencia de "concretamente identificable" es contradictoria con las categorías de "frutos", "cardúmenes", "minerales" a las que refiere la ley. En la ley modelo de la Cnudmi se habla de "razonable identificación," ${ }^{, 70}$ lo cual parece un concepto más amigable. ${ }^{71}$

- No recoge en forma amplia la posibilidad de constitución de la garantía prendaria sobre todo tipo de bienes futuros, ${ }^{72}$ evitando así cualquier tipo de discusión doctrinaria al respecto y tutelando efectivamente al acreedor para el caso del concurso. ${ }^{73}$

- No existen normas diferentes que tengan en cuenta la diferente perdurabilidad $^{74}$ de los bienes muebles.

- No se toma en cuenta expresamente la posibilidad de que la prenda recaiga sobre la totalidad de los bienes del garante. ${ }^{75}$

- No incluye en la prenda los bienes atribuibles, regulando en forma insuficiente los frutos y los productos sustitutivos y complementarios; exigiéndose para estos últimos inexplicablemente no solo el pacto expreso, sino que además se encuentren en el mismo lugar físico. ${ }^{76}$

- No se establecen categorías genéricas de bienes muebles ni se consideran diferentes sistemas para la oponibilidad de la garantía tomando en cuenta el tipo de bien o su categoría. ${ }^{77}$ No regula la situación de distintos tipos de bienes cuya prenda no será susceptible de inscripción registral, formulando

\footnotetext{
${ }^{70}$ Artículo 9.

71 "Pretender exigir, en todos los casos, una identificación precisa del bien mueble gravado con una garantía, conduce a eliminar la posibilidad de contar con alguna publicidad de gravámenes, que o bien son difíciles de identificar desde un principio, o bien cumplen una función económica que requiere su desaparición y reemplazo constante por otros bienes (por ejemplo, mercaderías, existencias comerciales de un comercio, una flota de automóviles, una serie de cuentas por cobrar)" (Gallino \& Ellerman, 2004, p.85).

${ }^{72}$ Como sí lo hace la ley modelo de la Cnudmi en su artículo 6.

${ }^{73}$ Groisman sostiene que, en realidad, en la ley uruguaya "no hay referencia alguna a bienes futuros, salvo el caso excepcional de la llamada 'prenda flotante', argumentando que dado que en el artículo 2 de la ley 17228 se establece que el dador conservará la tenencia de la cosa a nombre del acreedor, para ello necesariamente la cosa debe existir y ello es incompatible con la prenda sobre bienes futuros $(2019$, p. 839). 74 "Uno de los principales problemas que plantean los muebles, como objeto de garantía y como objeto de inscripción, es su perdurabilidad. [...] Por tanto, la garantía que recaiga sobre ellos debe tener en cuenta esta característica y ajustarse a ella" (García-Valdecasas, 2017, p. 363).

75 Tal como sí se establece expresamente en la ley modelo de la Cnudmi en su artículo 8.

76 También recogido en forma amplia en el artículo 10 de la ley modelo de la Cnudmi.

77 "El medio más idóneo para perfeccionar una garantía dependerá del bien en cuestión" (Gallino \& Ellerman, 2004, p. 84).
} 
soluciones que den certeza al momento de oponibilidad erga omnes del derecho real.

- No regula los posibles conflictos de prioridades entre los distintos sujetos, ${ }^{78}$ en especial la situación del adquirente en el curso ordinario de los negocios, ${ }^{79}$ y la de la propiedad utilizada como garantía de adquisición de esos mismos bienes.

- No ha logrado imponer en la práctica una solución al problema de las cesiones de créditos sucesivas sobre un mismo crédito, estableciendo un sistema de registro sencillo que dé prioridad al primero en el tiempo. ${ }^{80}$

- No incluye la posibilidad de ejecución extrajudicial, ${ }^{81}$ elaborando requisitos que den garantías suficientes al ejecutado y un sistema de responsabilidad del acreedor en caso de abuso.

- Aparece clara la limitación del sistema registral que debiera ser revisado para que el derecho instrumental permita la aplicación del derecho sustancial. El actual sistema requiere el ingreso al Registro del Contrato de Prenda, sujeto a múltiples observaciones y requisitos e incluso a un contencioso registral; en contraposición al sencillo sistema de ingreso electrónico de un formulario registral preimpreso estandarizado, con indicación genérica de los bienes alcanzados, que casi no permite motivos de rechazo u observación.

- La inscripción sobre una base personal, esto es el nombre del dador de la garantía, es acorde a los modernos sistemas, así como también la existencia de un sistema de base nacional; pero a ello debería adicionarse la posibilidad de aceptar errores que no sean gravemente engañosos en el nombre del dador

\footnotetext{
${ }^{78}$ El capítulo 5 de la ley modelo de la Cnudmi regula detalladamente las reglas de prelación entre acreedores concurrentes.

79 "Queda el problema de las existencias, es decir de aquellos bienes que constituyen el tráfico normal de la empresa que solicita financiación. [...] En términos generales no puede exigirse a los compradores o consumidores finales de esas existencias la consulta al registro para saber si las mismas están o no gravadas (García-Valdecasas, 2017, p. 365).

${ }^{80}$ Conforme reglamentación de las cesiones de créditos internacionales en el Convenio de las Naciones Unidas sobre la cesión de créditos en el Comercio Internacional de fecha 12 de diciembre de 2001.

81 "El régimen de ejecución elegido por la ley para esta modalidad de crédito prendario fue el judicial (acorde con el principio de jurisdiccionalidad imperante en nuestro medio) y por la vía de apremio como proceso autónomo" (Simón, 2000, p. 120).
} 
de la garantía, ${ }^{82}$ la existencia de un solo registro de base nacional a estos efectos para todos los bienes incluyendo vehículos automotores y derechos de propiedad intelectual.

\section{Conclusiones}

- El security interest, regulado en el capítulo 9 del Código de Comercio Uniforme de EE. UU. es una garantía real sobre bienes muebles de carácter voluntaria. Inicia la tercera generación de las garantías reales mobiliarias, caracterizada por la aplicación de la prenda sin desplazamiento en forma generalizada a todos los bienes, posibilitando en especial al deudor comerciante el uso de la cosa mientras la utiliza para hacerse de los fondos necesarios para su actividad comercial.

- La ley uruguaya de prenda sin desplazamiento del año 2000, se basó en este modelo anglosajón, aunque en forma imperfecta; es por ello que en este trabajo se intentó analizar el modelo anglosajón a los efectos de analizar los aspectos que debieran tenerse en cuenta para una futura reforma de la Ley n. ${ }^{\circ} 17.228$.

- Existe asimismo una tendencia mundial a seguir el modelo anglosajón, el cual ha sido analizado exhaustivamente y regulado con las diferencias necesarias en varios ámbitos, entre los que se destacan el ámbito de la OEA y de la Cnudmi, leyes modelo que se deben tener en cuenta especialmente en los países del civil law.

- El security interest anglosajón alcanza con amplitud a bienes muebles corporales e incorporales, presentes y futuros, incluyendo activos financieros y activos intangibles, derechos y créditos, que son clasificados en distintas categorías.

- Alcanza asimismo en forma automática al producido de los bienes dados en garantía; ya sea dinero o bienes muebles atribuibles, amplio concepto que permite dar funcionalidad al sistema y es de suma importancia en la etapa

\footnotetext{
${ }^{82}$ Véase que la ley modelo de la Cnudmi incluye un extenso capítulo sobre normas registrales, regulándose pormenorizadamente diferentes aspectos registrales de la garantía mobiliaria (capítulo 4).
} 
concursal; el concepto del tracing o trazabilidad que se funda en que lo relevante es el valor del bien prendado y no el bien específico en sí.

- El security interest se constituye mediante el cumplimiento de dos etapas netamente separadas: la etapa de attachment y la etapa de perfection.

- La etapa de attachment refiere a la adherencia del derecho real a la cosa, está dada por el contrato de garantía, debiendo existir una contraprestación del acreedor, legitimación para disponer de parte del dador de la garantía y un contrato auténtico, extendido en uno o varios documentos, del cual debe surgir la intención del dador de otorgar la garantía y una descripción suficiente de los bienes; esto es una identificación razonable de los mismos a través de la indicación de una categoría de bienes.

- La etapa de perfection es la fase externa que hace oponible el derecho real a terceros y la misma es diferente según la categoría de bienes involucrados. La regla general para lograr la oponibilidad a terceros es a través de la inscripción en el registro de una notificación inicial que da aviso de la existencia de esta garantía. Como excepción, en algunos casos la oponibilidad a terceros se obtendrá automáticamente con la suscripción del contrato de garantía (caso de la garantía mobiliaria de adquisición en productos de consumo a los efectos de proteger a quien vende productos de consumo a crédito); o mediante el control (en el caso de cuentas bancarias); o mediante la anotación en el título (en el caso de automóviles); o mediante la transferencia de la posesión (en el caso de títulos valores y valores negociables corporales para los cuales no es posible la consulta continua al registro). Se destaca la facilidad con la cual el derecho real deviene oponible a terceros, distinguiendo según las categorías de bienes, diferentes sistemas de oponibilidad que dan certeza y seguridad a los otorgantes de crédito.

- El formulario de inscripción registral o notificación inicial se inscribe en el registro por el nombre del dador de la garantía, admitiéndose errores menores en el nombre, no es necesaria la firma del dador de la garantía en el mismo por lo que este se inscribe electrónicamente y basta con una simple indicación de los bienes. Se inscribe de acuerdo a modelos aceptados y no existe casi posibilidad de observaciones al mismo por parte del registro. El 
sistema de registro es flexible y ágil y el acceso a dicha información muy sencillo.

- Este formulario funciona como una reserva de prioridad, ya que en la práctica su inscripción es anterior a la firma del contrato de garantía y la fecha de inscripción del formulario será la fecha que se tendrá en cuenta a los efectos de las reglas de prioridad. Luego de esta inscripción inicial no es necesario inscribir el contrato de garantía.

- El modelo anglosajón se ocupa especialmente de tutelar al comprador de buena fe que adquiere los bienes en el curso ordinario de los negocios del vendedor, el cual adquiere los bienes libres de la garantía.

- El modelo también regula la llamada garantía mobiliaria de adquisición, estableciendo para la misma un régimen de prioridad especial aun cuando se inscriba en forma posterior a otra garantía.

- El security interest permite que el acreedor garantizado cobre el $100 \%$ de su deuda de los bienes alcanzados por la garantía, en caso de concurso o quiebra del dador de la garantía, con la seguridad de que esta garantía alcanza al producido de los bienes muebles originalmente prendados.

- En caso de incumplimiento y necesidad de ejecución de la garantía, la parte 6 del capítulo 9 establece un proceso expeditivo, formado por dos etapas: la de aprehensión de los bienes y la de enajenación de los mismos. La primera etapa puede ser extrajudicial (con el único límite de no que se afecte la paz) o judicial; la segunda etapa de enajenación es enteramente extrajudicial con el único límite de que la enajenación sea "comercialmente razonable”.

- El capítulo 9 analizado se aplica a todas las transacciones por las que sin importar su forma se crea una garantía real sobre bienes muebles, pero también a otras situaciones tutelando al comprador de cuentas a cobrar, al consignatario y al arrendador en ciertos casos, tal como si fueran acreedores garantizados.

- Al analizar este tipo de garantía, impacta la amplia aceptación del mismo en el mundo comercial anglosajón y la facilidad y agilidad con la que se puede 
constituir un security interest, una visión pragmática que permite que sea posible y hasta usual que una persona física o jurídica comience una actividad comercial con una garantía sobre la totalidad de sus bienes; todo lo cual además es de suma trascendencia y aplicación en el comercio internacional.

- La regulación detallada de este instituto en más de setecientos artículos del Código de Comercio Uniforme de EE. UU. (9-101 a 9-809) que prevén de antemano un sinnúmero de situaciones que se pueden presentar en la etapa de preparación del security interest, de constitución del mismo, de oponibilidad, de cumplimiento, de conflicto de prioridades, de incumplimiento y de ejecución muestran una realidad sumamente diferente a la escueta ${ }^{83}$ ley de prenda sin desplazamiento uruguaya, que ha dejado sin resolver buena parte de las interrogantes y aparece como una tímida propuesta frente a la laboriosidad con que el derecho americano se ha ocupado de regular las garantías mobiliarias.

- Como se ha visto, la búsqueda de un equilibrio entre los intereses de todos los actores que pueden verse afectados por el funcionamiento de esta garantía, teje una elaborada regulación, la cual se ha intentado replicar a lo largo del mundo.

- La pregunta es si se tendrá la capacidad de trasladar con practicidad estos conceptos al derecho uruguayo, logrando la seguridad jurídica necesaria que garantice al empresario la obtención de crédito para su actividad. Es necesario un giro más pronunciado hacia el modelo que plantea el sistema del common law, con una mayor protección del acreedor para incentivar el crédito, regulando las diferentes situaciones que pueden producirse de forma de no descuidar la situación del dador de la garantía y del consumidor.

- No se propone una idea tan ambiciosa como la de englobar toda operación de garantía sobre bienes muebles bajo un único concepto, tal como lo ha hecho el modelo anglosajón aquí analizado, pero sí complementar en base a

${ }^{83}$ Tal como señala De Cores, es una ley "muy concisa y poco clara y naturalmente no se puede basar una ley en dos o tres artículos que son los que regulan el tema desde el punto de vista civil” (2002, p. 87). 
los conceptos analizados la regulación actual del instituto de la prenda mobiliaria para que esta pueda ser utilizada con mayor éxito y seguridad jurídica en el desarrollo del crédito y del comercio.

En definitiva, como respuesta a la pregunta que surge del título del presente artículo, se entiende que es conveniente la regulación detallada del security interest en el derecho uruguayo, tomando en cuenta la ley madre anglosajona así como los aportes de las leyes modelo referidas, que contemplan realidades del civil law y con las adaptaciones necesarias al sistema local.

Sí es posible una alternativa a los bienes inmuebles como medio de garantía, su escaso éxito es debido a deficiencias legislativas más que a la propia naturaleza de

los bienes muebles, y los bienes que pueden servir de garantías son tantos y tan variados y pueden ofrecer tanta seguridad, como los clásicos bienes inmuebles [...] A la vista de todo lo dicho podemos concluir afirmando con Javier Gómez Gálligo que el siglo XXI va a ser el siglo de los bienes muebles García-Valdecasas, 2017, pp. 368 y 374.

\section{Referencias}

Cooper, C. (2000). The New Article Nine, Uniform Commercial Code. Estados Unidos: American Bar Association.

De Cores, C. (2002). Ley de prenda sin desplazamiento. Revista de Derecho, 1(2), 8589.

De Cores, C. (2008). El nuevo derecho de las garantías reales: Estudio comparado de las recientes tendencias en materia de garantías reales mobiliarias. Buenos Aires: Reus.

Epstein, D. G., Nickles, S. H., Smith, E. (2003). Nine Questions: Secured Debt Deals in the $21^{\text {st }}$ Century. Minnesota: Thomson West.

Francia. (2006, marzo 23). Ordenanza n. ${ }^{\circ}$ 346. Recuperado de https://www.legifrance.gouv.fr/loda/id/JORFTEXT000000639090/

Gallino, J. \& Ellerman, I. (2004). Garantías mobiliarias internacionales. Anuario de Derecho Civil, 9, 67-119.

García-Valdecasas, J. A. (2017). Sobre el registro de bienes muebles y garantías mobiliarias: su futuro en España. En F. J. Valenzuela Garach, F. J. PérezSerrabona (Coord.), Reformas en Derecho de Sociedades (357-376). Madrid: Marcial Pons. 
Groisman, C. (2019). Relevancia de la cosa futura en la contratación. Anuario de derecho civil uruguayo, 50, 825-842.

Harris, S. L. \& Mooney, C. W. (2016). Security Interests in Personal Property, Cases, Problems and Materials. Minnesota: LEG.

Italia. (2016, mayo 3). Ley n. ${ }^{\circ} 119$. Recuperado de https://www.gazzettaufficiale.it/eli/id/2016/07/02/16G00128/sg

Naciones Unidas. (2012). Guide to Enactment of the Uncitral Model Law on Public Procurement. Naciones Unidas. Recuperado de https://uncitral.un.org/en/texts/procurement/modellaw/public_procurement/guide

Naciones Unidas. (2016). Ley Modelo de la Cnudmi sobre Garantías Mobiliarias. Recuperado de https://uncitral.un.org/es/texts/securityinterests/modellaw/secured_transactions

Organización de Estados Americanos [OEA]. (2002). Ley Modelo Interamericana sobre Garantías Mobiliarias. Recuperado de https://www.oas.org/es/sla/ddi/docs/garantias_mobiliarias_Ley_Modelo_Interam ericana.pdf

Roca Sastre, R. (1968). Derecho Hipotecario. Barcelona: Bosch.

Simón, L. M. (2000). La ejecución de crédito prendario registrado en la reciente Ley 17.228. Revista Uruguaya de Derecho Procesal 1/2000.

Uruguay. (2000, enero 7). Ley n. ${ }^{\circ}$ 17.228: Ley de Prenda sin Desplazamiento. Recuperado de https://www.impo.com.uy/bases/leyes/17228-2000

Walt, S. D. \& Warren, W. D. (2019). Commercial Law Selected Statutes (2018-2019). Estados Unidos: Foundation Press.

Wonsiak, M. \& Curbelo, C. (2000). Ley de Prenda, Encuentros Técnicos Regionales, Versión Taquigráfica. Montevideo: Asociación de Escribanos del Uruguay.

\section{Contribución autoral}

a) Concepción y diseño del trabajo; b) Adquisición de datos; c) Análisis e interpretación de datos; d) Redacción del manuscrito; e) revisión crítica del manuscrito.

I. P. ha contribuido en a, b, c, d, e.

Editora científica responsable: Dra. María Paula Garat. 